\title{
A developed method for the measurement of $\mathrm{CO}_{2}$ solubility in $\mathrm{NaCl}$ solutions under geological conditions via fused silica capillary cell with in-situ Raman spectroscopy

\author{
Zhiyan Pan ${ }^{1}$, Junliang Wang ${ }^{2}$
} \\ ${ }^{1}$ College of Environment, Zhejiang University of Technology, Hangzhou 310032,China, panzhiyan@zjut.edu.cn ${ }^{2}$ College of Environment, Zhejiang University of Technology, Hangzhou 310032, China, upupwang@zjut.edu.cn
}

The measure of $\mathrm{CO}_{2}$ solubility in geological fluids is important for carbon capture and storage (CCS). A method using a fused silica capillary cell (FSCC), combined with confocal Raman spectrometer, has been developed to determine the $\mathrm{CO}_{2}$ solubility in $\mathrm{NaCl}$ solutions. The microscale FSCC was constructed to reduce the temperature gradient and reagent consumption. Raman spectroscopy was used to verify the system reached phase equilibrium based on the fact that the intensity of Raman scattering is proportional to the molecular concentration of $\mathrm{CO}_{2}$ under given conditions. The $\mathrm{CO}_{2}$ solubility data were calculated from the Raman peak intensity ratio $\left(v_{\mathrm{CO}_{2}} / v_{\mathrm{H}_{2} \mathrm{O}}\right)$ in $\mathrm{CO}_{2}$ saturated solutions and the equation relating Raman peak intensity ratio and $\mathrm{CO}_{2}$ concentration in $\mathrm{NaCl}$ solutions. The measured $\mathrm{CO}_{2}$ solubilities ranged from 0.3036 to $1.2790 \mathrm{~mol} \cdot \mathrm{kg}^{-1}$ in 1.0 $\mathrm{mol} \cdot \mathrm{kg}^{-1} \mathrm{NaCl}$ solution, from 0.2528 to $1.0348 \mathrm{~mol} \cdot \mathrm{kg}^{-1}$ in $2.0 \mathrm{~mol} \cdot \mathrm{kg}^{-1} \mathrm{NaCl}$ solution, and from 0.2126 to 0.8931 $\mathrm{mol} \cdot \mathrm{kg}^{-1}$ in $3.0 \mathrm{~mol} \cdot \mathrm{kg}^{-1} \mathrm{NaCl}$ solution at temperatures from $30^{\circ} \mathrm{C}$ to $80^{\circ} \mathrm{C}$ and pressures from $3.0 \mathrm{MPa}$ to $30.0 \mathrm{MPa}$. Our results indicate that the method is feasible and that the solubility of $\mathrm{CO}_{2}$ in $\mathrm{NaCl}$ solutions decreases with increasing temperature or salinity, increases with increasing pressure. On the basis of a comparison between our experimental data and the results of the previous model, our method provides satisfactory results. 